\title{
A Comparative study to measure the horizontal condylar guidance obtained by protrusive interocclusal records and panoramic radiographic images in completely edentulous patients
}

\author{
Arjun Bhandari, ${ }^{1}$ Archana Manandhar, ${ }^{2}$ Raj Kumar Singh, ${ }^{3}$ Pramita Suwal, ${ }^{3}$ Prakash Kumar \\ Parajuli $^{3}$ \\ ${ }^{1}$ Department of Prosthodontics, ${ }^{2}$ Department of Conservative Dentistry and Endodontics, Gandaki Medical \\ College, Pokhara, Nepal, ${ }^{3}$ Department of Prosthodontics, B. P. Koirala Institute of Health Sciences, Dharan- \\ 18 , Nepal
}

\section{Correspondence}

Dr. Arjun Bhandari

Department of Prosthodontics, Gandaki Medical College,

Pokhara, Nepal

Email:

arjunnbhandari@gmail.com

DOI: http://dx.doi.org/10.3126/ jemsn.v14i1.18947

Orcid ID: orcid.org/0000-0002 $-1555-2065$

Article received: Jan $7^{\text {th }} 2018$ Article accepted: Mar $22^{\text {nd }} 2018$

\begin{abstract}
Background \& Objectives: The study was conducted with objective to compare the horizontal condylar guidance (HCG) obtained by protrusive interocclusal records and panoramic radiographic images in completely edentulous patients. Materials \& Methods: The horizontal condylar guidance was measured in 25 completely edentulous patients by protrusive interocclusal records using zinc oxide eugenol paste through a face bow transfer (HanauTM Spring bow, Whip Mix Corporation, USA) to a semi-adjustable articulator (HanauTM Wide-Vue Articulator, Whip Mix Corporation, USA). In the same patients, HCG was traced in the panoramic radiograph. The angles formed by the intersection of two lines: Frankfurt's horizontal plane and posterior slope of articular eminence was measured using protractor to represent the horizontal condylar guidance angle on each side. Results: The mean difference between the horizontal condylar guidance angles values obtained using protrusive interocclusal record and panoramic radiograph was 2.68 degrees and 3.40 degrees for the right and the left side respectively, with the panoramic radiograph values being higher. This difference between the values was found to be highly significant between the two methods for the right side $(t=2.70, p=0.012)$ and left side $(t=3.69, p=0.001)$. A significant positive correlation was found between the horizontal condylar guidance obtained from protrusive interocclusal record and panoramic radiograph for the right $(\mathrm{r}=0.643, \mathrm{p}=0.001)$ and left sides $(\mathrm{r}$ $=0.622, p=0.001)$ separately. Conclusion: The panoramic radiographic tracing can be used to calculate the mean horizontal condylar guidance in the completely edentulous patients and these values can be used to programme semi-adjustable articulators avoiding the cumbersome process of obtaining protrusive interocclusal records.
\end{abstract}

Key words: Horizontal condylar guidance; panoramic radiograph; protrusive interocclusal records

Citation: Bhandari A, Manandhar A, Singh RK, Suwal P, Parajuli PK. A Comparative study to measure the horizontal condylar guidance obtained by protrusive interocclusal records and panoramic radiographic images in completely edentulous patients. JCMS Nepal. 2018;14(1):21-7.

\section{INTRODUCTION}

Stomatognathic system is a dynamic unit with mandible as the only part capable of independent motion. It is necessary to simulate the similar movements while fabricating a prosthesis which is done on an articulator. The mandibular movement can be conferred as condylar movement. The recording of mandibular movements become essential during the restorative as well as Prosthodontic treatment as they influence the cusp angles and developmental grooves in the posterior teeth. In addition to this, it becomes mandatory for making complete denture to provide balanced occlusion in it. 'Condylar guidance is the mandibular guidance generated by the condyle and articular disc traversing the contour of glenoid fossa. 
It is also defined as the mechanical form located in the upper posterior region of an articulator that control movement of its mobile member.' Horizontal condylar guidance is the mechanical equivalent of condylar guidance i.e. the angle formed by the path of the condyle, within the horizontal plane compared with the median plane. The most popular technique for determination of the horizontal condylar guidance is by the use of protrusive interocclusal record..$^{3-6}$ The recording of protrusive and lateral interocclusal records in completely edentulous patient become difficult and cumbersome as the record base in many instances becomes loose and unstable. Furthermore, the patient's inability to hold the mandible in protrusive and lateral position till the intercocclusal material sets, due to the absence of periodontal proprioceptors, make such records erroneous and fallacious in many instances. ${ }^{7}$ The various literatures $^{8-10}$ indicate the use of radiograph for recording the condylar guidance. Panoramic radiograph is routinely used for the diagnosis in completely edentulous patient. Gilboa et $\mathrm{al}^{10}$ through the study on dry human skulls, evaluated the outline of the articular eminence and the glenoid fossa of the temporal bone on panoramic radiographs and suggested to be of valuable aid in determining condylar guidance angle in semiadjustable articulators. Hence, this study was carried out to compare the inclination of the condylar path obtained by panoramic radiograph and protrusive interocclusal records in completely edentulous patient.

\section{MATERIALS AND METHODS}

The ethical clearance for this study was obtained from "The Institute Protocol and Ethical Committees". A total of 25 completely edentulous patients reporting to the Department of Prosthodontics, College of Dental Surgery, BPKIHS, for replacement of missing teeth were selected according to the inclusion and exclusion criteria. The written informed consent was taken from all the patients enrolled. Inclusion criteria included completely edentulous patient with wellformed ridges, good neuromuscular control, adequate inter-maxillary space, orthognathic jaw relation. Exclusion criteria included patient with temporomandibular disorders, inadequate control of jaw movements and conditions that contraindicates the use of radiograph.

Recording horizontal condylar guidance setting by protrusive interocclusal record:
The protrusive interocclusal record was taken at the maxillo-mandibular relationship recording stage. Maxillary cast was mounted on Semi-adjustable articulator (HanauTM Wide-Vue Articulator, Whip Mix Corporation, USA) using face bow (HanauTM Spring bow, Whip Mix Corporation, USA) transfer. Mandibular cast was mounted using patient's centric relation record. Centric relation record was verified by Gothic arch tracing The patient was trained to move the mandible forward till the stylus rests in marked point on transparent radiograph film attached to tracing table of Hight tracer. The protrusive interocclusal record was made at $6 \mathrm{~mm}$ protrusion by using zinc oxide eugenol paste (DPI Impression Paste, Mumbai, India).[Figure 1]. The record was then transferred to articulator. The right and left horizontal condylar guidance were set and the locknuts were secured with positive finger pressure. [Figure 2]

Recording horizontal condylar guidance setting by tracing from panoramic radiograph

The panoramic radiograph taken for screening purpose was used for obtaining horizontal condylar guidance angle. Radiograph was taken in the Department of Oral Medicine and Radiology with panoramic radiographic unit (Orthoralix 9200 DDE;

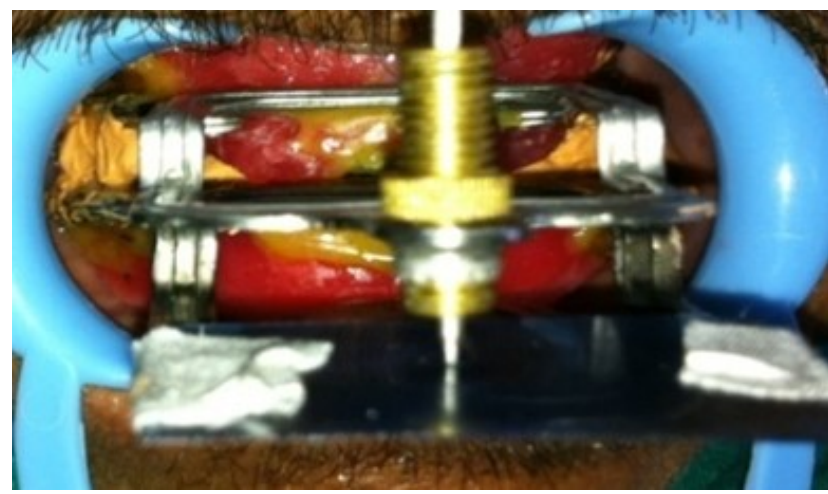

Figure 1: Protrusive interocclusal record with Zinc oxide Eugenol

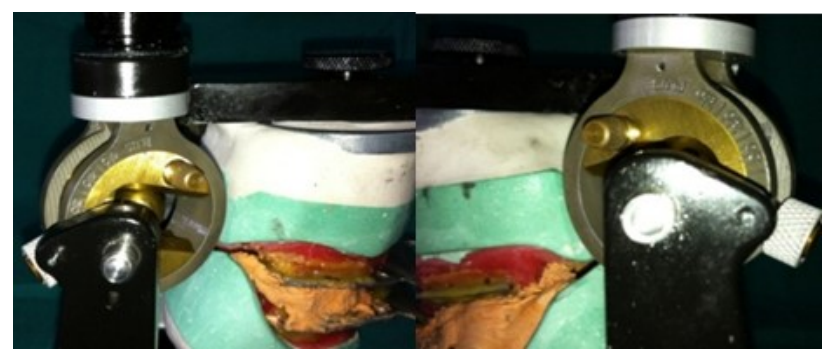

Figure 2: Condylar guidance angle obtained on semi-adjustable articulator using protrusive interocclusal records. 


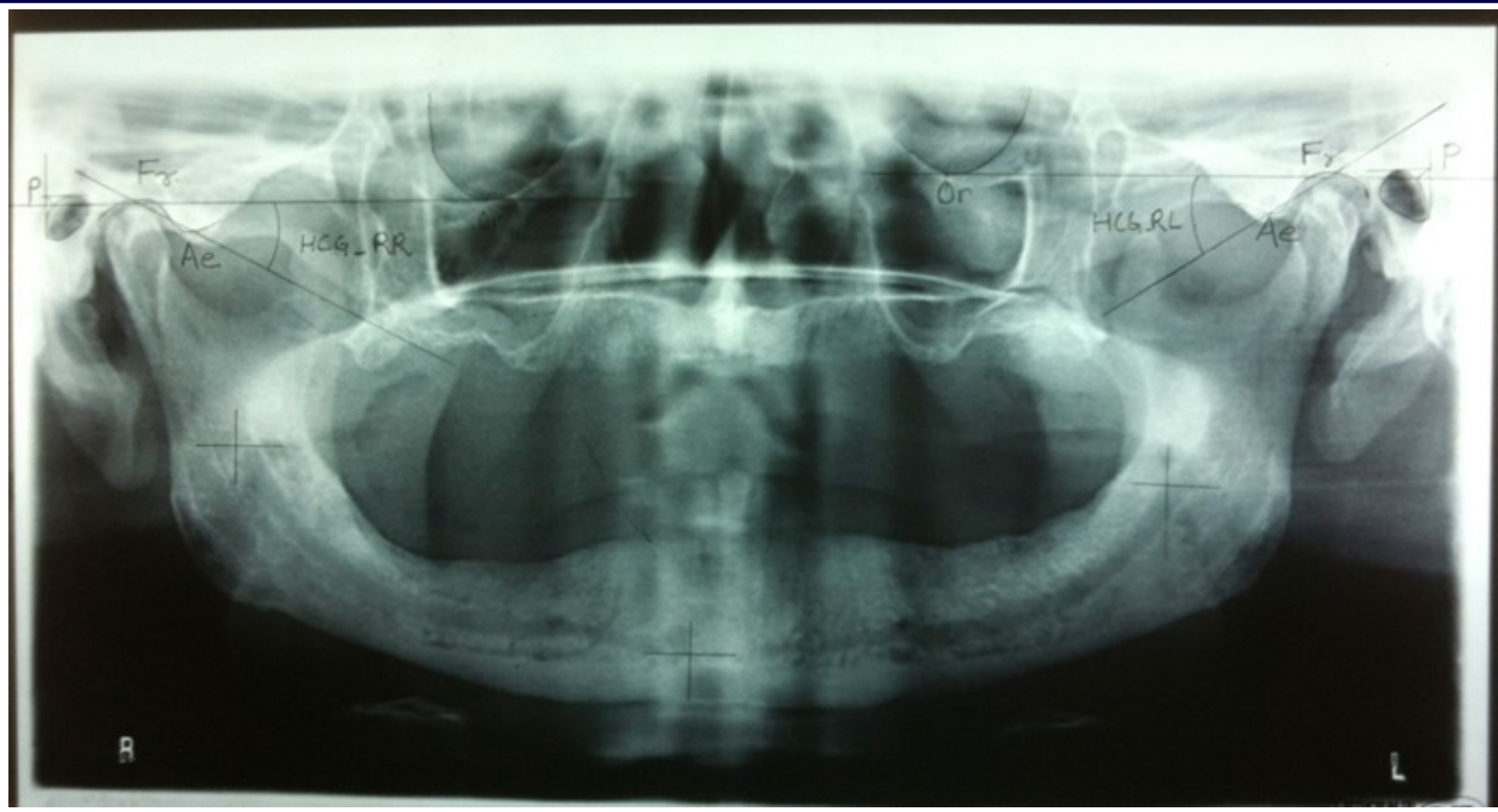

Figure 3: Panoramic radiograph showing tracing of horizontal condylar guidance angle.

Gendex, U.S.A). The images were acquired at (6684) $\mathrm{kVp},(3-15) \mathrm{mA}$ and 12 seconds, according to the built of the patient. Tracings on the radiograph were done using $(0.003$ inch) acetate tracing paper with an $\mathrm{HB}$ pencil $0.3 \mathrm{~mm}$ (Steadler made, Germany); three reference marks were made to align the tracing paper over the radiograph. A panoramic radiographic image in the temporal region shows the outer radio-opaque line representing the articular eminence and glenoid fossa and inner radio-opaque line representing the inferior border of zygomatic arch.10 The left and right orbitale (Or), lowest point in the margin of the orbit and porion $(\mathrm{P})$, highest point on the auditory meatus were identified. These two reference points were joined by straight line representing the Frankfurt horizontal plane. The most superior point on the glenoid fossa (Fr) and the most inferior point on articular eminence (Ae) were identified and marked. The two reference points ( $\mathrm{Fr}$ and Ae) were joined by a straight line representing posterior slope of articular eminence. The angles formed by the intersection of two lines: Frankfurt's horizontal plane (P-Or) and posterior slope of articular eminence (Fr-Ae) was measured using protractor to represent the horizontal condylar guidance angle on each side. [Figure 3]

\section{Statistical analysis}

All the data were entered in the Microsoft Excel sheet 2007 and subsequently analyzed using SPSS (Statistical Package for Social Sciences) software version 11.5. Paired $\mathrm{t}$ - test was used to compare the mean difference between the right and left horizontal condylar guidance angles obtained by protrusive interocclusal record and panoramic radiographic methods. Paired $\mathrm{t}-$ test and Pearson's correlation test were applied to check the mean difference and correlation of HCG angles obtained by two methods on both the right and left sides. Tests were done at $95 \%$ confidence interval. A p value of $\leq 0.05$ was considered for statistical significance.

\section{RESULTS}

The data obtained from 25 completely edentulous patients (18 male, 7 female) from the eastern part of Nepal, who came to Department of Prosthodontics, college of Dental Surgery, B.P. Koirala Institute of Health Sciences, Dharan, Nepal, for replacement of missing teeth, were recorded in the study.

The mean horizontal condylar guidance angle obtained from protrusive interocclusal record in the right side was found to be $21.32 \pm 5.31$ degrees and in the left side was found to be $21.08 \pm 5.55$ degrees. The mean horizontal condylar guidance angle obtained from tracings of panoramic radiograph in the right side was found to be $24.00 \pm 6.24$ degrees and in the left side was found to be $24.48 \pm 4.96$ degrees. (Table 1) The mean difference between the horizontal condylar guidance angles values on right and left sides obtained using protrusive interocclusal record was 0.24 degrees (SD- 3.55). 
Table 1: Distribution of horizontal condylar guidance angle values obtained from both methods

\begin{tabular}{|lllll|l|} 
Particulars & $\begin{array}{l}\text { Number } \\
\text { (N) }\end{array}$ & $\begin{array}{l}\text { Minimum } \\
\text { (degrees) }\end{array}$ & $\begin{array}{l}\text { Maximum } \\
\text { (degrees) }\end{array}$ & $\begin{array}{l}\text { Mean } \\
\text { (degrees) }\end{array}$ & $\begin{array}{l}\text { Standard } \\
\text { Deviation }\end{array}$ \\
\hline HCG_PR & 25 & 10 & 30 & 21.32 & 5.31 \\
\hline HCG_PL & 25 & 5 & 28 & 21.08 & 5.55 \\
\hline HCG_RR & 25 & 13 & 33 & 24.00 & 6.24 \\
\hline HCG_RL & 25 & 13 & 32 & 24.48 & 4.96
\end{tabular}

HCG PR - $\quad$ Right horizontal condylar guidance angle obtained from protrusive interocclusal record. HCG_PL - Left horizontal condylar guidance angle obtained from protrusive interocclusal record. HCG_RR Right horizontal condylar guidance angle obtained from panoramic radiograph. HCG_RL Left horizontal condylar guidance angle obtained from panoramic radiograph

Table 2: Comparison between mean HCG angles obtained on right and left side using both methods

\begin{tabular}{llllll} 
Particulars & \multicolumn{2}{l}{ Paired differences } & t value & p value & Inferences \\
& Mean & SD & 0.33 & 0.738 & $\begin{array}{l}\text { Not } \\
\text { Significant }\end{array}$ \\
\hline HCG_PR-HCG_PL & 0.24 & 3.55 & 0.54 & 0.588 & $\begin{array}{l}\text { Not } \\
\text { Significant }\end{array}$ \\
\hline HCG_RR-HCG_RL & 0.48 & 4.37 & & &
\end{tabular}

Table 3: Comparison between mean HCG angles obtained using protrusive interocclusal record and panoramic radiograph.

\begin{tabular}{llclll} 
Particulars & \multicolumn{2}{c}{ Paired differences } & t value & p value & Inferences \\
& Mean & SD & & & \\
\hline HCG_PR -HCG_RR & -2.68 & 4.95 & 2.70 & 0.012 & Significant \\
\hline HCG_PL - HCG_RL & -3.40 & 4.60 & 3.69 & 0.001 & Significant
\end{tabular}

Table 4: Correlation between HCG angles obtained using protrusive interocclusal record and panoramic radiograph on right and left sides.

\begin{tabular}{llll} 
Particulars & Pearson's correlation (r) & p-value & Inferences \\
\hline HCG_PR / HCG_RR & 0.643 & 0.001 & Significant \\
HCG_PL/ HCG_RL & 0.622 & 0.001 & Significant
\end{tabular}

The mean difference between the horizontal condylar guidance angles values on right and left sides obtained using panoramic radiographic tracing was 0.48 degrees (SD- 4.37). This difference between the values was found to be insignificant between the right and left side $(t=0.33, p=0.738)$ obtained using protrusive interocclusal record and $(\mathrm{t}$ $=0.54, \mathrm{p}=0.588$ ) obtained using panoramic radiographic tracing. (Table 2) The mean difference between the horizontal condylar guidance angles values obtained using protrusive interocclusal record and panoramic radiograph was 2.68 degrees and 3.40 degrees for the right and the left side respectively, with the panoramic radiograph values being higher. This difference between the values was found to be highly significant between the two methods for the right side $(\mathrm{t}=2.70, \mathrm{p}=0.012)$ and left side $(\mathrm{t}=3.69, \mathrm{p}=0.001)$ (Table 3$)$ A significant positive correlation was found between the horizontal condylar guidance obtained from protrusive interocclusal record and panoramic radiograph for the right $(\mathrm{r}=0.643, \mathrm{p}=0.001)$ and left sides $(r=0.622, p=0.001)$ separately. (Table 4) 


\section{DISCUSSION}

Diagnosis and treatment of a patient for a prosthetic rehabilitation requires the fabrication of diagnostic casts, master casts and articulate them on an articulator. It is mandatory to record the maxillomandiblular relationship and accurately transfer it to an articulator. The face bow transfer followed by the use of centric, protrusive and lateral jaw relation records together aid in establishing the simulation of mandibular movements on an articulator. ${ }^{11}$ It allows the clinician to calculate the correlation between the path traced by the condyles during mandibular movements and the occlusal morphology of posterior artificial teeth which in turn aids in restoring the occlusion without interferences, leading to the long term rehabilitation of function and preservation of alveolar bone. ${ }^{12}$

In clinical practice, protrusive interocclusal records are the most commonly used to adjust different types of semi-adjustable articulators for measuring the horizontal condylar guidance $(\mathrm{HCG})^{3-6,}$ however the reliability of this method has been questioned by various researchers. ${ }^{6,13-15}$ Craddock $^{16}$ and Posselt et $\mathrm{al}^{17}$ have recommended to keep the distance of protrusion constant as far as possible as some correlation exists between the degree of protrusion and value of HCG angle. However, it becomes difficult to maintain a constant amount of protrusion in the completely edentulous individuals for quite long duration till the recording material sets as they already loose the proprioceptors along with their natural teeth. In this study the protrusion was approximately $6 \mathrm{~mm}$ for all patients. As an alternative to this conventional method of registration of protrusive interocclusal record to obtain HCG angle, orthopantomograph has been used in later periods by different researchers in the dentate individuals. ${ }^{18,19}$ In this study, the conventional method of protrusive interocclusal records and the panoramic radiographs were used to obtain the values for horizontal condylar guidance (HCG) angle in the completely edentulous individuals.

In this study, the variations of HCG angle ranged between 10 degrees to 30 degrees and 5 degrees to 28 degrees for the right and left side respectively from the protrusive interocclusal record. The variations of $\mathrm{HCG}$ angle measured from the panoramic radiograph was found to be 13 degrees to 33 degrees and 13 to 32 degrees for right and left side respectively. These data are consistent with those of previous studies by Zamacona et al, ${ }^{12}$ Hobo and Mochizuki, ${ }^{20}$ Lundeen and Wirth, ${ }^{21}$ Preti et al., ${ }^{22}$ dos Santos et al, ${ }^{6}$ Csado et $\mathrm{al}^{23}$ who found wide variations of HCG angle ranging from 5 degrees to 55 degrees. Due to these differences between individuals, there would be little justification for using articulators in which inclination cannot be adjusted. $^{12}$ Coming to the study per se, the mean horizontal condylar guidance (HCG) obtained from the use of protrusive interocclusal record in the right side was found to be 21.32 degrees (SD 5.31) and that in the left side was 21.08 degrees (SD - 5.55). Similarly, the mean HCG obtained with the panoramic radiograph in the right side was found to be 24 degrees (SD - 6.24) and that in the left side to be 24.48 degrees (SD -4.96). By observing the results of both the techniques, it could be inferred that the HCG in the right and left sides of temporomandibular joint are nearly symmetrical with the difference being statistically nonsignificant $(\mathrm{p}$ value -0.738 for protrusive record method and $\mathrm{p}$ value -0.588 for radiographic method). Literature suggests that the right and left eminences rarely have the same slants and contours. $^{24}$ The smaller mean differences between the right and left $\mathrm{HCG}$ angles are in accordance with the studies done by Csado et al, ${ }^{23}$ Shrestha et al, ${ }^{25}$ Prasad et al. ${ }^{19}$ These values are statistically not significant but clinically and radiographically, the value of HCG angles was higher in the right side as compared to the left side. This difference might be attributed to the chewing patterns that most of the individuals favor the right side for chewing which could be related to more wear of the right articular eminence as compared to the left. Previous studies $^{18,19}$ which were conducted in dentate individuals reported that the mean $\mathrm{HCG}$ angles were higher than that of the present study which was conducted in completely edentulous patients. Csado et $\mathrm{al}^{23}$ reported the mean $\mathrm{HCG}$ angles obtained by panoramic radiograph in dentulous individuals were higher than that of the completely edentulous individuals and concluded the correlation of flattening of articular eminence could be related to ageing. They also found the rate of deformation is significantly higher in completely edentulous individuals than the individuals with maintained occlusion. The findings from the present study and Csado et $\mathrm{al}^{23}$ suggested that it is necessary to provide the prosthetic and occlusal rehabilitation after the extractions for the prevention of the anatomical changes in the temporomandibular joint. Another comparison was 
performed between the mean HCG obtained by protrusive interocclusal record and those obtained by radiographic method for both the right and left side of the temporomandibular joints using paired $t$ - test. The result of this comparison revealed that the mean HCG angle obtained by the radiographic method was greater than those obtained by the protrusive interocclusal record method that were statistically significant for both the right side ( $p$ value- 0.012) and the left side ( $p$ value0.001). These findings of the study might be justified with any of the following reasons. First, the panoramic radiographic method usually gives higher value than actual which was also shown by Gilboa et $a 1^{10}$ in their study where they found the sagittal condylar inclination to be seven degrees greater on an average than its actual anatomic outline in the dry skulls. Second, the occlusal rims when kept in protruded mandibular position and held by the completely edentulous individuals, they would have generated a significant pressure on the mucosa of denture basal seat. That would depress the resilient oral mucosa ultimately bringing the inter-ridge distance closer, resulting a narrower triangular wedge shaped space between the posterior part of occlusal rims, analogous to the Christensen's space seen in natural dentition, which is recorded by the protrusive interocclusal records ultimately showing the lesser value for HCG when placed in semi-adjustable articulators. A moderately strong positive correlation was found between the mean values of horizontal condylar guidance (HCG) angles obtained by protrusive interocclusal record and radiographic method for the both right and left sides of temporomandibular joints using Pearson's correlation test ( $\mathrm{r}-0.643$ and $\mathrm{p}$ - value $<0.001$ for the right side and $\mathrm{r}-0.622$ and $\mathrm{p}$ value $<0.001$ for the left side). Previous study ${ }^{10}$ also found the positive correlation between the radiographic image of the horizontal condylar inclination and its actual anatomic outline in dry skulls. The study by Prasad et $\mathrm{al}^{19}$ reported the positive correlation between HCG angle values obtained by protrusive interocclusal record and panoramic radiograph in dentulous individuals. Due to the inaccuracies of the interocclusal record technique with inherent errors of up to 30 degrees, ${ }^{6}$ the radiographic articular eminence may have clinical significance10. It is suggested that such tracings can be drawn relative to a horizontal reference plane like the Frankfurt plane and the resulting condylar guidance angles to adjust the condylar guidance of semi-adjustable articulators.

\section{CONCLUSION}

The mean HCG obtained by protrusive interocclusal records and panoramic radiographic tracings among the edentulous patients can be well compared with minimal higher values for the radiographic method. Hence the panoramic radiographic tracing can be used to calculate the mean horizontal condylar guidance in the completely edentulous patients and these values can be used to programme semi-adjustable articulators avoiding the cumbersome process of obtaining protrusive interocclusal records. However, further similar studies are required in larger scale to draw a definite conclusion.

\section{Funding}

\section{None}

\section{Conflict of Interest Statement:}

None Declared

\section{REFERENCES}

1. Okeson JP. Management of Temporomandibular disorders and occlusion. 6th ed. St. Louis: Elsevier; 2008.

2. The Glossary of Prosthodontics Terms. J Prosthet Dent. 2005;94:10-92

j.prosdent.2005.03.013.

3. Rosenstiel SF, Land MF, Fujimoto J. Contemporary fixed prosthodontics. 4th ed. St. Louis: Mosby; 2006. p. 71.

4. Curtis DA. A comparison of protrusive interocclusal records to pantographic tracing $\mathrm{J}$ Prosthet Dent. 1989;62:154-6. https://doi.org/10.1016/0022-3913(89) 90303-X.

5. Ecker GA, Goodacre CJ, Dykema RW. A comparison of condylar control settings obtained from wax interocclusal records and simplified mandibular motion analyzers. J Prosthet Dent. 1984;51:404-6. https://doi.org/10.1016/0022 -3913(84)90231-2.

6. Dos Santos J Jr., Nelson S, Nowlin T. Comparison of condylar guidance setting obtained from a wax record versus an extraoral tracing: A pilot study. J Prosthet Dent. 2003;89:54-59. https://doi.org/10.1067/mpr.2003.11. PMID: 12589287.

7. Rahn AO, Heartwell CM. Textbook of complete dentures. 5th ed. Pennsylvania: Lea and Febiger; 1993.p.250-1, 298.

8. Boos RH .Condylar path by roentgenograph. J Prosthet Dent. 1951;1:387-92. https://doi.org/10.1016/0022-3913 (51)90022-4.

9. Katsavrias EG. The effect of mandibular protrusive (activator) appliances on articular eminence morphology. Angle Orthod. 2003;73:647-53. PMID: 14719728.

10. Gilboa I, Cardash HS, Kaffe I, Gross MD. Condylar guidance: correlation between articular morphology and panoramic radiographic images in dry human skulls. J Prosthet Dent. 2008;99:477-82. https://doi.org/10.1016/ S0022-3913(08)60112-2.

11. Sharma LA, Azhagarasan NS, Chitra Shankar, Sharma A.Comparative study of the effect of three different interocclusal recording materials and reproducibility of horizontal condylar registrations in two different semiadjustable articulators: A clinical study. Int J Prosthodontics \& Restorative Dentistry. 2011;1:155-62. https://doi.org/10.5005/jp-journals-10019-1029. 
12. Zamacona JM, Otaduy E, Aranda E. Study of the sagittal condylar path in edentulous patients. J Prosthet Dent 1992;68:314-7. https://doi.org/10.1016/0022-3913(92) 90336-9.

13. Gross M, Nemcovsky C, Friedlander LD. Comparative study of condylar settings of three semiadjustable articulators. Int J Prosthodont. 1990;3:135-41. PMID: 2133380.

14. Donegan SJ, Christensen LV. Sagittal condylar guidance as determined by protrusion records and wear facets of teeth. Int J Prosthodont. 1991;4:469-72. PMID: 1811642.

15. Gross M, Nemcovsky C, Tabibian Y, Gazit E. The effect of three different recording materials on the reproducibility of condylar guidance registrations in three semi-adjustable articulators. J Oral Rehabil. 1998;25:204-8. https:// doi.org/10.1046/j.1365-2842.1998.00225.x. PMID: 9578229.

16. Craddock FW: The accuracy and practical value of records of condylar path inclination. J Am Dent Assoc. 1949;38:697-710. jada.archive. 1949.0066 .

17. Posselt U, Franzen C. Registration of the condyle path inclination by intraoral records: Variation in three instruments. J Prosthet Dent. 1960;10:441-54. https:// doi.org/10.1016/0022-3913(60)90047-0.

18. Tannamala PK, Pulagam M, Pottem SR, Swapna B. Condylar Guidance: Correlation between Protrusive Interocclusal Record and Panoramic Radiographic Image: A Pilot Study. J Prosthodont. 2012;21:181-4. https:// doi.org/10.1111/j.1532-849X.2011.00811.x. PMID: 22339685.

19. Prasad DK, Shah N, Hegde C. A clinic-radiographic analysis of sagittal condylar guidance determined by protrusive interocclusal registration and panoramic radiographic images in humans. Contemp Clin Dent. 2012;3:383-7. https://doi.org/10.4103/0976-237X.107419. PMID: 23633793.

20. Hobo S, Mochizuki S: Study of mandibular movements by means of an electronic measuring system. Part II. J Jpn Soc. 1982;26:635-53

21. Lundeen HC, Wirth CG: Condylar movement patterns engraved in plastic blocks. J Prosthet Dent. 1973;30:86675. https://doi.org/10.1016/0022-3913(73)90280-1.

22. Preti G, Scotti RS, Bruscagin C. A clinical study of graphic registration of the condylar path inclination. J Prosthet Dent. 1982;48:461-6. https://doi.org/10.1016/0022-3913 (82)90086-5.

23. Csado K, Marton K, Kivovics P. Anatomical changes in the structure of the temporomandibular joint caused by complete edentulousness. Gerodontology. 2012;29:111-6. https://doi.org/10.1111/j.1741-2358.2011.00498.x. PMID: 21605161.

24. Aull AE. Condylar determinants of occlusal patterns. J Prosthet Dent. 1965:15;826-49. https:// doi.org/10.1016/0022-3913(65)90122-8.

25. Shreshta P, Jain V, Bhalla A, Pruthi G.A comparative study to measure the condylar guidance by the radiographic and clinical methods. J Adv Prosthodont. 2012;4:153-7. https:// doi.org/10.4047/jap.2012.4.3.153. PMID: 22977723. 